\title{
Aproximaciones foucaulteanas para pensar la tortura en el Cono Sur latinoamericano: una revisión ${ }^{*}$
}

\author{
Foucaultean approaches to thinking about torture in the Latin American \\ Southern Cone: a review
}

\author{
Mariela Cecilia Avila** \\ Tuillang Yuing Alfaro**
}

\begin{abstract}
Resumen: El presente trabajo busca desarrollar una reflexión filosófica sobre la pertinencia del uso de categorías foucaulteanas para abordar la tortura durante las últimas dictaduras militares del Cono Sur latinoamericano. Para ello, se hará una revisión del corpus analítico desplegado por Michel Foucault sobre el poder punitivo y sus mecanismos. Todo ello con la intención de vislumbrar un posible uso y rendimiento de ciertas categorías para pensar nuestro reciente pasado histórico-político.
\end{abstract}

Palabras clave: tortura, filosofía, dictadura militar, Latinoamérica, Foucault

\begin{abstract}
This work seeks to develop a philosophical reflection over the relevance of the use of Foucault's categories in order to think about the torture situations during the last military dictatorships in Latin American Southern Cone. In order to do that, the analytical corpus about punitive power and it mechanisms developed by Michel Foucault will be used and related to the work of Latin Americans intellectuals will be review. All this will be done with the intention to see a possible use and performance of some categories in order to think about our historical and political recent past.
\end{abstract}

Key words: torture, philosophy, military dictatorship, Latin America, Foucault

Recibido: 12 junio 2016

Aceptado: 23 septiembre 2016

\footnotetext{
* Este trabajo forma parte del Proyecto Postdoctoral FONDECYT $\mathrm{N}^{\circ} 3140089$ "Análisis filosófico de los campos de prisioneros del Cono Sur a partir de los aportes de Hannah Arendt y Giorgio Agamben", y del Proyecto FONDECYT Regular N 1140200 "Campos de prisioneros en Chile. Reconfiguración de los lugares y las subjetividades"

** Argentina, coautora, Doctora en Filosofía por la Pontificia Universidad Católica de Valparaíso y por la Universidad Paris 8 Saint-Denis. Académica de la Escuela de Filosofía de la Universidad Católica Silva Henríquez, mavila@ucsh.cl

${ }^{* * *}$ Chileno, coautor, Doctor en Filosofía por la Pontificia Universidad Católica de Valparaíso, Instituto Asuntos Públicos Universidad de Chile y Escuela de Salud Pública, Universidad de Chile, tuillangyuing@gmail.com
} 


\section{Introducción}

Como bien indica el título de este trabajo, nuestra intención es esbozar una reflexión de carácter filosófico sobre la tortura, y si bien esta categoría ha sido ya abordada desde diversos marcos, en este caso, buscamos dar a este análisis una raigambre histórica, al vislumbrarlo desde una perspectiva latinoamericana. La presente línea de reflexión se dirige entonces, a pensar el lugar y la pertinencia del trabajo de Foucault en relación al análisis del ejercicio de la tortura y sus espacios de excepción durante las últimas dictaduras del Cono Sur latinoamericano.

Más precisamente, nuestro propósito es abordar una discusión teórico-filosófica que permita evaluar y hacer precisiones respecto del uso de algunas categorías foucaulteanas en el análisis y lectura de cuestiones políticas. A nuestro juicio, la utilización de los insumos proporcionados por la analítica del poder que Foucault fue desarrollando a partir de la década del setenta, conduce en ocasiones a algunos excesos y sobre-interpretaciones que parecen alejarse de sus propósitos iniciales. Esto puede observarse de modo particular, en las reflexiones que Giorgio Agamben ha llevado a cabo sobre la categoría de biopolítica. No obstante, lejos de condenar esto, preferimos revisar su pertinencia, pues creemos que las ideas del propio Foucault bien podrían convertirse en una certera cantera para pensar otros sucesos y contextos políticos.

Ahora bien, no es nuestra intención, al menos en este caso, desplegar una genealogía o una analítica sobre las formas y métodos de tortura ${ }^{1}$, sino que lo que nos interesa, es desarrollar una posible reflexión que vaya en la línea de la comprensión -en sentido arendtiano ${ }^{2}$ - de ciertos sucesos de nuestro reciente pasado histórico-político. Este ejercicio nos permitirá, en última instancia, arrojar ciertas luces sobre el presente, particularmente sobre el modo en que nos constituimos como sujetos políticos, marcados por un pasado dictatorial signado por una violencia, que aún hoy persiste y nos configura.

\footnotetext{
1 Para profundizar este problema, véase: Reszczynski, Katia, Rojas, Paz y Barceló Patricia. Tortura y resistencia en Chile, Santiago de Chile, Ediciones Radio Universidad de Chile, 2013; García Villegas, René, Soy Testigo. Dictadura, tortura, injusticia. Santiago de Chile, Editorial Amerindia, 1990 y Mendiola, Ignacio, Habitar lo inhabitable. La práctica político-punitiva de la tortura, Barcelona, Edicions Bellaterra, 2014. Respecto a un análisis psicomédico y social de la tortura y sus consecuencias, sobre todo en Chile y Argentina, véase la publicación del Seminario Internacional: Tortura, aspectos médicos, psicológicos y sociales. Prevención y tratamiento. Editado por el Equipo de denuncia, investigación y tratamiento del torturado y su núcleo familiar del Comité de Defensa de los Derechos del Pueblo, Santiago, 1990.

${ }^{2}$ Hannah Arendt caracteriza la comprensión como un complejo proceso, que dice relación con el modo en que se reconoce y asume un acontecimiento novedoso. Su análisis dice relación con el fenómeno del totalitarismo, que deja en evidencia que el primer impulso humano es asimilar los sucesos nuevos a lo conocido, para finalmente reconocer que lo novedoso e inesperado puede suceder en la historia. Este complejo proceso de comprensión implica la reconfiguración, e incluso, la creación de herramientas para analizar y reflexionar sobre aquellos sucesos que interpelan el razonamiento, y que resultan desconocidos con anterioridad en la historia. Para profundizar esta categoría analítica arendtiana Cfr. Arendt, Hannah, “Comprensión y política. Las dificultades de la comprensión." Disponible en: www.omegalfa.es/titulos.php?letra=\&pagina=3
} 
Si bien esta indagación tiene una clara signatura foucaulteana, el trabajo de algunos intelectuales latinoamericanos que se han dedicado a pensar tanto la dictadura militar, como la tortura y sus consecuencias, nos permitirá ampliar la reflexión. De esta manera, el análisis genealógico que Foucault desarrolla principalmente en Vigilar y castigar, será el punto de partida para evaluar el uso de ciertas categorías para pensar sucesos afincados en Latinoamérica.

Ahora bien, el presente trabajo no busca erigirse como juez de los usos y abusos que ha tenido el pensamiento de Foucault. Por el contrario, y tal como hiciera el propio Foucault con el pensamiento de Nietzsche, creemos que es posible "(...) utilizarlo, deformarlo, hacerlo chirriar, gritar." "3 Lo que de ninguna manera implica abandonar el rigor y la seriedad que merece toda reflexión.

\section{Mirar a través de la lente de foucaulteana y más allá}

Ahora bien, para comenzar, nos preguntamos ¿de dónde viene la vinculación de la analítica del poder foucaulteana con la comprensión de fenómenos de excepcionalidad política como la violencia de Estado, los campos de concentración, el terrorismo de Estado, y de modo especial, con la tortura, en tanto problema que anima este escrito?

Si intentamos establecer una suerte de recorrido de esta vinculación, debemos referirnos al trabajo de Giorgio Agamben, quien en el primer volumen de su saga Homo Sacer, del año 1995, El poder soberano y la nuda vida ${ }^{4}$, se sirve de la noción de biopolítica como clave para una re-interpretación de la política de occidente, según un paradigma en que el poder captura la vida bajo la forma de una inclusión-exclusiva. En este contexto, Agamben se permite hacer un cruce entre la biopolítica y los análisis de Arendt sobre el totalitarismo y los campos de concentración. Con ello, el sintagma "biopolítica" es indicativo del sentido profundo en que el derecho incluye la vida en el mismo gesto por el cual puede llevarla a la muerte bajo la forma del sacrificio. De esta manera, para el italiano "los lugares por excelencia de la biopolítica moderna" son "el campo de concentración y la estructura de los grandes Estados totalitarios del siglo XX."5

De la mano de Agamben, la biopolítica abre un abanico de posibilidades analíticas que dicen relación con la vida, esta vez, como nuda vida: aquella vida desnuda a la que cualquiera puede dar muerte, pues se encuentra exceptuada del ámbito humano, pero también del divino, y por lo tanto, es sacrificable. Es en este panorama, precisamente, donde el campo de concentración, amparado en el estado de excepción, toma el estatuto de un paradigma que ilumina la conformación del orden político, así como sus estructuras e instituciones posibles.

Por cierto, hay que notar que la interpretación de Agamben no ha estado exenta de críticas y objeciones. En general, ellas apuntan a la deshistorización de la categoría de

\footnotetext{
${ }^{3}$ Foucault, Michel, Microfísica del poder, Madrid, La Piqueta, 1992, p. 110

${ }^{4}$ Agamben, Giorgio, Homo sacer I. El poder soberano y la nuda vida, Valencia, Pre-textos, 2006

${ }^{5}$ Ibíd., p., 12.
} 
biopolítica, la que, en manos de Foucault, nunca fue extraída de un recorte histórico y temporal claramente delimitado ${ }^{6}$. De este modo, se acusa a Agamben de ontologizar y elevar a una esencia metafísica un problema que debe ser atendido siempre a un nivel de inmanencia. Otros, como Rancière ${ }^{7}$, han señalado que la posición de Agamben no ha hecho sino retornar la mirada productiva que sobre el poder había dirigido Foucault, hacia su momento de pura negatividad y violencia, invisibilizando las formas concretas por las cuales el poder se efectúa y pone en forma.

No obstante estas críticas, esta aproximación ha ganado cierto rédito y ha dejado no pocos aportes que tienden, en definitiva, a hacer de Foucault $-\mathrm{y}$, en especial, de la biopolítica- un referente propicio para el análisis y estudio de episodios donde se dan cita la excepcionalidad política, el totalitarismo, el terrorismo de estado y sus prácticas micropolíticas de persecución, tortura, confinamiento y desaparición ${ }^{8}$.

En general, creemos que muchos de estos aportes encierran la posibilidad de establecer una línea de investigación interesante, que se sirva de lo desarrollado por Foucault para ser dirigido a problemas que no fueron atendidos por el francés. No obstante, creemos también que para que ello sea verdaderamente provechoso, se necesita refinar las categorías propuesta por Foucault, hacer distinciones y establecer matices respecto de las distintas racionalidades en las que se enmarcan sus categorías. En buena medida, avanzar un paso en esta elucidación, es el propósito de este escrito.

A lo anterior se suma una cierta confusión. La analítica del poder propuesta de modo metodológico por Foucault desde Vigilar y castigar, y profundizada en el primer

\footnotetext{
${ }^{6}$ Véase al respecto, Castro, Edgardo, Lecturas foucaulteanas. Una historia conceptual de la biopolítica, UNIPE, La Plata 2011, Karmy, Rodrigo, Políticas de la interrupción. Ensayos sobre Giorgio Agamben. Escaparate, Santiago, 2011; Mulhe, María, "Sobre la vitalidad del poder: una genealogía de la biopolítica a partir de Foucault y Canguilhem" En: Lemm, Vanessa, Michel Foucault: neoliberalismo y biopolítica, Ediciones Universidad Diego Portales, 2010. Para una síntesis del debate, cfr. Salinas, Adán. La semántica biopolítica. Foucault y sus recepciones. Cenaltes Ediciones, Madrid, 2014.

${ }^{7}$ Véase, Rancière, Jacques. “¿Biopolítica o política?” En: El Tiempo de la igualdad. Herder, Barcelona, 2011. Un análisis de esta crítica se desarrolla en Avila, Mariela. "Entre policía y políticas. Derivas de un concepto filosófico" En: Yuing, Tuillang y Karmy, Rodrigo Biopolíticas, Gobierno y Salud Pública. Ocho libros, Santiago, 2014.

${ }^{8}$ Al respecto véase: Raffin, Marcelo. La experiencia del horror. Subjetividad y derechos humanos en las dictaduras y posdictaduras del Cono Sur. Del Puerto, Bs. As, 2006, Calveiro, Pilar. Poder y desaparición. Los campos de concentración en Argentina. Colihue, Bs. As. 2008, Peris Blanes, Jaume. La imposible voz. Memoria y representación de los campos de concentración en Chile: la posición del testigo. Cuarto propio. Santiago, 2005, Thayer, Willy. El fragmento repetido. Escritos en estado de excepción. Metales pesados, Santiago, 2006, Cassigoli, Isabel: "El derecho del Estado (de excepción) y la política del hombre” En: Karmy, Rodrigo, Políticas de la interrupción. Ensayos sobre Giorgio Agamben. Escaparate, Santiago, 2011. Reyes Mate, Manuel, Memoria de Auschwitz. Actualidad moral y política. Trotta, Madrid, 2003. Traverso, Enzo, La historia como campo de batalla. Interpretar las violencias del siglo XX. Fondo de Cultura Económica, Buenos Aires, 2012. García, Raúl. Micropolíticas del cuerpo. De la conquista de América a la última dictadura militar. Biblos, Bs. As., 2000., Mendiola, Ignacio, Habitar lo inhabitable. La práctica políticopunitiva de la tortura, Barcelona, Edicions Bellaterra, 2014 y Avila, Mariela, "Dictaduras Latinoamericanas y campos de concentración. Una reflexión filosófica necesaria”, En: Santos José (ed.), Dictadura y prisión política en Chile, Santiago de Chile, Editorial Pehuén, 2016.
} 
volumen de La historia de la Sexualidad, La voluntad de saber, enfatiza la productividad del poder y su carácter sutil para no involucrarse directamente con el cuerpo. La célebre sentencia del alma como la cárcel del cuerpo, gana en ese sentido, fuerza y relevancia en la medida que permite una gestión de la conducta y de la subjetividad que no pasa por un acto de violencia manifiesta. Sin embargo, esta obra arranca en un momento anterior, de radical oposición y violencia, que se revela como la ocasión de mayor severidad de la relación entre el poder y el cuerpo. Aludimos obviamente al episodio de la tortura Damiens. En efecto, en el apartado Suplicio Foucault abre el análisis con una descripción detallada y cruda de la condena de Damiens, para posteriormente comparar dicha escena con un reglamento para la casa de jóvenes delincuentes de Paris. Si bien retomaremos nuevamente este punto con mayor detenimiento, interesa mostrar que la crudeza y patetismo de la tortura y suplicio de Damiens pueden hacer olvidar que precisamente la racionalidad que permitía dicha ejecución y dicha aplicación del poder, cae en retirada con la emergencia de las disciplinas. En efecto, es en las disciplinas y su despliegue dónde la analítica del poder propuesta por Foucault revela su novedad. No obstante, si se lee Vigilar y castigar con la mirada puesta de modo especial en la tortura de Damiens, siempre estará la tentación de hacer equivalente este análisis con otras prácticas de tortura que pueden estar esta vez, mucho más relacionadas con los sucesos políticos ligados a la excepcionalidad política y legal ${ }^{9}$.

De allí que consideremos pertinente esbozar esta reflexión, que busca, precisamente, analizar y evaluar la posible valía del uso del pensamiento de Foucault para pensar diversos sucesos y acontecimientos políticos. En este sentido, consideramos necesario indicar la existencia de ciertas dificultades metodológicas y conceptuales que se presentan. Acudir principalmente al marco categorial que Foucault aborda en Vigilar y castigar para pensar la tortura en el contexto latinoamericano, más que coincidencias y caminos analíticos allanados, pone en vista problemas y giros conceptuales de aparente irresolución que queremos exponer. Este trabajo del año 1975 lleva por subtítulo El nacimiento de la prisión, lo que se presenta ya como un escollo. En efecto, el nombre de la obra adelanta una reflexión que se dirige a mostrar de modo concreto e histórico las mutaciones que el castigo y la institución penitenciaria han tenido a partir del siglo XVIII.

Ahora bien, esta demarcación conceptual y temporal supone un problema si lo que se busca es analizar sucesos que se sitúan en otro contexto histórico, político, e incluso, territorial. Además, es necesario enfatizar que el fenómeno de la tortura dictatorial, se localiza topológica y topográficamente al margen de todo sistema punitivo legal. Tanto la violencia que recae sobre los cuerpos, como los campos de concentración del Cono Sur, son efecto de un ámbito de ilegalidad, o para decirlo en términos de Giorgio Agamben, de anomia $^{10}$. Es decir, durante las últimas dictaduras militares, las instituciones concentracionarias y el ejercicio de la tortura, se ampararon en Estados ilegítimos, cuya

\footnotetext{
${ }^{9}$ De algún modo, es lo que creemos advertir en algunos pasajes del libro de Raúl García, Micropolíticas del cuerpo, Op., Cit., y también, aunque con claras diferencias, en el texto de Ignacio Mendiola Habitar lo inhabitable La práctica político punitiva de la tortura, Op., Cit.

${ }^{10}$ Cfr., Agamben, Giorgio, Estado de Excepción, Buenos Aires, Adriana Hidalgo, 2007.
} 
forma jurídica fue la de la excepcionalidad, que es la que finalmente confiere la posibilidad de actuar sin ninguna forma de referente o represalia jurídica.

Esbozamos así esta primera dificultad, que será luego retomada, para dar paso a otro problema que dice relación con la perspectiva analítica y epistemológica presente en Vigilar y castigar, pues en el apartado El cuerpo de los condenados, Foucault explica el modo en que el suplicio y la tortura cambian de estatuto a finales del siglo XVIII. Para ello, como hemos indicado, al comienzo de la obra, narra cuidadosamente el suplicio que le es infringido a Damiens, acusado de parricidio por haber intentado asesinar al rey en el año 1757. El texto de Foucault comienza de la siguiente manera: "Damiens fue condenado, el 2 de marzo de 1575, a <pública retractación ante la puerta principal de la Iglesia de París>, adonde debía ser <llevado y conducido en una carreta, desnudo, en camisa, con un hacha de cera encendida de dos libras de peso en la mano> (...)"11

Sin entrar en mayores detalles, pues estos quedan suficientemente expuestos en el texto de Foucault, sólo diremos que el cuerpo de Damiens es sometido a formas de tortura extremas, a vista y paciencia de todo el pueblo. En efecto, en este contexto, tanto el espacio de la plaza pública, como los ojos del pueblo, se convierten en testigos del cumplimiento total de la sentencia que pesa sobre el acusado, y que se materializa bajo la forma del suplicio.

Al momento de definir la figura del suplicio, Foucault acude a las palabras de Louis de Jaucourt ${ }^{12}$, quien indica que se trata de una "pena corporal, dolorosa, más o menos atroz (...) Es un fenómeno inexplicable lo amplio de la imaginación de los hombres en cuestión de barbarie y de crueldad" ${ }^{\prime 3}$. No obstante, esta práctica no es ajena al ámbito penal, sino que responde a un "código jurídico del dolor" 14 .

Como ya hemos señalado, inmediatamente a continuación de la exposición del caso de Damiens, Foucault muestra en su texto el reglamento de la Casa de jóvenes delincuentes de París, redactado por León Faucher ${ }^{15}$. En este documento es posible vislumbrar un exhaustivo reparto del tiempo y los lugares, así como también, de las tareas y movimientos de los prisioneros. Cada minuto tiene una ocupación asignada, cada movimiento una finalidad determinada, y cada espacio, un empleo específico. Si tomamos, por ejemplo, el artículo $\mathrm{N}^{\circ} 17$ de este reglamento, leemos: "La jornada de los presos comenzará a las seis de la mañana en invierno, y a las cinco en verano. El trabajo durará nueve horas diarias en toda estación. Se consagrarán dos horas al día a la enseñanza. (...)" . ${ }^{16}$ Podemos observar

\footnotetext{
${ }^{11}$ Foucault, Michel, Vigilar y Castigar. Nacimiento de la prisión, 2005, p., 11

${ }^{12}$ Louis de Jacourt fue un filósofo, médico y escritor francés del siglo XVIII, gran colaborador de Diderot y d'Alembert en la escritura de L'Encyclopédie. Su interés político y social, relativo a los derechos de los ciudadanos y la necesidad de abolir la esclavitud, explican en gran medida sus reflexiones sobre el suplicio y el sistema carcelario.

${ }^{13}$ Foucault, 2005, Op. Cit., p., 39

${ }^{14}$ Ibid, p., 40

${ }^{15}$ Este texto, De la réforme des prisions, que busca distinguir la cárcel común establecida por penas juzgadas de los lugares de arresto, fue publicado en el año 1838, y los beneficios obtenidos de su venta fueron destinados en su totalidad a los jóvenes liberados de la Maison de jeunes détenus à Paris.

${ }^{16}$ Foucault, 2005, Op., Cit., p., 14
} 
un minucioso reparto de los cuerpos en el espacio y el tiempo, que más allá de considerar las horas del día, incorpora las diferentes estaciones en su calendarización.

Sin embargo, se observa que en el caso del reglamento de la Casa de jóvenes delincuentes de París, a diferencia de lo que ocurre con el suplicio de Damiens, los cuerpos y las actividades de los jóvenes prisioneros se despliegan en un ámbito cerrado y vedado a los ojos de la población. Con estos dos ejemplos, Foucault da cuenta de los cambios y las mutaciones relativas al lugar y a la visibilidad que adquiere el encierro y el castigo en un breve periodo de tiempo histórico. No obstante, indica que más allá de esta importante diferencia -que finalmente genera un cambio de estatuto en la economía de la tortura-, en ambos casos y con diversos métodos, el fin que se persigue es el mismo: dar cumplimiento a un castigo. En este contexto, lo que le interesa mostrar a Foucault es el desplazamiento de una tecnología afianzada en la tortura, el dolor y la violencia física, hacia un dispositivo de carácter cuadricular, que casi no contempla contacto físico, en el que los cuerpos están cuidadosamente situados y predispuestos en el espacio y el tiempo.

Así, al exponer estos dos casos de carácter e índole tan diferente, y separados tan sólo por tres cuartos de siglo, Foucault evidencia dos formas de economía penal, que a todas luces representan dos tecnologías distintas del castigo, que responden a diferentes racionalidades políticas. En vistas a lo anterior, desarrolla un análisis, en el que muestra el modo en que el castigo se desprende finalmente de ese contexto teatral y espectacular que lo había caracterizado durante los siglos anteriores. Se clausura así esa teatralidad que exponía el cuerpo de los condenados a los ojos del gran público, frente al cual, los actores eran obligados a representar un papel que cobraba realidad en el dolor de sus heridas laceradas. El gran escenario comienza a cerrar su telón, para albergar, casi con vergüenza, tras bambalinas, aquellas vidas culpables de delito que, de todas maneras, era necesario castigar y reformar.

Foucault explica como alrededor de la década del 20' del siglo XIX, el modo de aplicación del castigo sufre una suerte de torsión, pues pasa a formar parte de un ámbito cerrado, incluso privado. Ya no es posible observar aquellas escenas sangrientas de antaño, desplegadas en las plazas o en las calles, sino que, por el contrario, todo atisbo de visibilización del castigo ha quedado encerrado, es decir, fuera del rango de observación de la población. En vistas a lo anterior, tanto la arquitectónica desplegada en torno al castigo, como sus andamiajes institucionales y gubernamentales, cambian su localización y sus modos de operar. A este respecto indica Foucault:

El castigo tenderá, pues, a convertirse en la parte más oculta del proceso penal. Lo cual lleva consigo varias consecuencias: la de que abandona el dominio de la percepción casi cotidiana, para entrar en el de la consciencia abstracta; se pide su eficacia a su fatalidad, no a su intensidad visible; es la certidumbre de ser castigado, y no ya el teatro abominable, lo que debe apartar del crimen; la mecánica ejemplar del castigo cambia sus engranajes. $^{17}$

\footnotetext{
${ }^{17}$ Foucault, 2005, Op., Cit., p., 17
} 
No obstante, hay que notar que este cambio de engranaje no está dado solamente por el ocultamiento del castigo, sino también por la desaparición del suplicio. En efecto, la economía de la penalidad efectúa una suerte de giro respecto al modo en que el castigo recae sobre el cuerpo del preso, pues su tarea se corresponde ahora con la cura del alma del prisionero, y no ya con una suerte de venganza o represalia por los delitos cometidos.

En este sentido, es interesante destacar que las ciencias humanas -aquellas a las que Foucault atendió en Las palabras y las $\operatorname{cosas}^{18}$ - deben también su desarrollo al sistema disciplinario que permitió acotar a los hombres espacial y temporalmente, al menos lo suficiente para que de ellos pudiese conformarse en un objeto de saber. Del mismo modo, el estatuto adquirido por estos saberes como "ciencias humanas", permitió una gestión del poder más adecuada y, por cierto, más justificada. Entre las hipótesis que guían Vigilar y castigar, Foucault señala: "En lugar de tratar la historia del derecho penal y de las ciencias humanas como dos series separadas [...] buscar si no existe una matriz común y si no dependen ambas de un proceso de formación <epistemológico-jurídico>; en suma situar la tecnología del poder en el principio tanto de la humanización de la penalidad como del conocimiento del hombre." 19

En efecto, esta complementariedad otorga sentido a la entrada del alma en el ámbito penal, y con ella la inserción en la práctica judicial de todo un saber <científico>. Para Foucault, la atención dirigida al alma -de la que los saberes psi son su mayor exponente-, indica una dislocación en los modos en que el cuerpo está atravesado por relaciones de poder. En este contexto cobra vigor su célebre sentencia: "El alma, efecto e instrumento de una anatomía política; el alma, prisión del cuerpo." 20

A partir de lo anterior, el sistema penal comienza a asentarse en otras formas de punición, que ya no se centran de modo particular en el dolor y el padecimiento físico de antaño. De esta manera, según Foucault, es posible percibir cómo la puesta en escena del suplicio dio lugar a otra forma de castigo más cercana a la privación, pasando a quedar relegado el cuerpo a un segundo plano. Precisamente, es la suspensión de ciertos derechos, bienes y libertades lo que cae ahora bajo la categoría de acto punitivo. Dice Foucault:

El cuerpo, según esta penalidad, queda prendido en un sistema de coacción y de privación, de obligaciones y de prohibiciones. El sufrimiento físico, el dolor del cuerpo mismo, no son ya los elementos constitutivos de la pena. El castigo ha pasado de un arte de las sensaciones insoportables a una economía de los derechos suspendidos. ${ }^{21}$

\footnotetext{
${ }^{18}$ Foucault, Michel. Las palabras y las cosas. Una arqueología de las ciencias humanas. Siglo XXI Editores, Buenos Aires, 2003.

${ }^{19}$ Foucault, 2005, Op., Cit., p., 30

${ }^{20}$ Foucault, 2005, Op., Cit., p., 36.

${ }^{21}$ Foucault, 2005, Op., Cit., p., 18
} 
De esta forma, podríamos pensar que nos encontramos frente a una mirada aséptica del castigo, que ya no osa rozar el cuerpo del prisionero, y que cuando debe hacerlo por necesidad, tal roce es mínimo y breve, centrado en no producir dolor innecesario, sino en finalizar cuanto antes la tarea que obliga a trascender los márgenes del contacto fisiológico. Sin embargo, Foucault aclara que el sistema punitivo nunca se ha mantenido completamente ajeno al dolor, ni siquiera a partir de la torsión que acabamos de describir, pues desde su constitución primera, ha estado relacionado con penas, golpes y privaciones. Y en este sentido, sería posible pensar que el cuerpo de los prisioneros, sigue siendo blanco de violencia y castigo, que ahora, sin embargo, adquieren una nueva perspectiva práctica y analítica.

En este sentido, la pregunta que nos permitimos realizar es, ¿hasta dónde estos aportes habilitan el análisis de otros episodios políticos en los que la tortura ha tenido también un papel fundamental? En definitiva, ¿cuál es el rendimiento de los análisis de Foucault para pensar la tortura en las dictaduras latinoamericanas? Trataremos de dar cuenta de esto en el siguiente apartado.

\section{La tortura dictatorial: entre la vigilancia y el castigo. Elementos para una revisión}

Si bien es necesario detenerse en el cambio que, según Foucault, sufre el aparato penal, y sobre todo el castigo a partir del siglo XIX, abrazar dicho cambio sin contemplar la posibilidad de estadios intermedios, impediría un acercamiento a los episodios que se vinculan al ejercicio y finalidad de la tortura dictatorial en el Cono Sur. En efecto, durante estos periodos hubo ciertos sucesos que podrían pensarse como una sofisticada reactivación del suplicio, debido tanto a la crudeza y violencia de sus prácticas, como a su doble juego de visibilidad e invisibilidad frente a los ojos de la población. En este sentido, pareciera que la matriz oculta de las formas de castigo, cercana a un poder disciplinar, hubiera perdido parte de su invisibilidad estructural al quedar expuestos los tormentos del castigo dictatorial sobre los cuerpos de los reaparecidos y en los cadáveres que amanecían en la vía pública. Comienzan a reflejarse aquí ciertas dificultades, que surgen al intentar compatibilizar sin ninguna clase de mediación categorías cuyo origen explicativo dice relación con otro tipo de sucesos histórico-políticos.

En esta línea, comenzamos diciendo que si bien acordamos con Flavio Guglielmi cuando indica que durante los regímenes militares del Cono Sur se implementó un procedimiento mixto de castigo, al mantener las cárceles con prisioneros "legales" y los campos de concentración con presos "políticos",22, no consideramos que esto sea suficiente

\footnotetext{
${ }^{22}$ Guglielmi, Flavio Iván, Los métodos punitivos y la economía de castigo durante la última dictadura cívico-militar argentina. ¿El regreso del poder soberano?, S/D, En:

http://hum.unne.edu.ar/postgrado/eventos/coloquio_filo/coloquio_filo.htm
} 
para usar sin más las categorías analíticas relativas al nacimiento de la prisión que presenta Michel Foucault. Como se indicó ya, el subtítulo de Vigilar y Castigar, el Nacimiento de la prisión, supone un problema conceptual, pues Foucault sitúa su análisis en un ámbito jurídico reconocido $\mathrm{y}$, en tanto tal, legal, y las reflexiones relativas a las dictaduras militares, aunque se hayan sostenido en un sistema mixto, erigieron espacios institucionales donde se instauró la violencia, la tortura y el dolor como modus operandi. Estos espacios amparados en la ilegalidad y la ilegitimidad, los campos de concentración, se diseminaros por los territorios nacionales durante los procesos dictatoriales, ocupando y resignificando lugares tales como viviendas particulares, escuelas, hospitales, teatros, barcos y dependencias policiales, entre otros.

A partir de esto, se podría considerar que las indagaciones situadas en el Cono Sur no guardarían relación con el ámbito analítico desplegado por Foucault, principalmente porque sus análisis nada tendrían que ver con dictaduras ni espacios de excepción, como los campos de concentración. Y más aún, si consideramos que antecedentes histórico-políticos, como el nazismo y sus Lager $^{23}$, no han sido una problemática a la que Foucault haya dedicado más de un breve análisis en alguna clase de alguno de sus cursos ${ }^{24}$.

Sin embargo, y por el otro lado, resulta igualmente plausible pensar que la dinámica punitiva que Foucault analiza en Vigilar y Castigar podría ser una útil herramienta para pensar las dictaduras del Cono Sur latinoamericano. Desde esa perspectiva, el trabajo de Foucault $^{25}$ permitiría ver el modo en que tanto el castigo como el suplicio, velados en un ámbito penal regular, desplegarían todo su potencial asesino en un contexto signado por la excepción dictatorial. Sin embargo, como ya hemos señalado, es Agamben y no el propio Foucault quien permite aventurar estos supuestos, sobre todo si se considera que la apuesta del italiano va en la línea de mostrar que el poder de la soberanía de "hacer morir y dejar vivir" no desaparecería de las lógicas disciplinarias ni de las de regulación poblacional, sino que permanecería latente para emerger en momentos de excepcionalidad legal. En efecto,

\footnotetext{
${ }^{23}$ Hemos trabajado con anterioridad de manera profusa la posibilidad de considerar el Lager nazi como un antecedente de los campos de concentración latinoamericanos. Al respecto, Cfr. Avila, Mariela, "Dictaduras Latinoamericanas y campos de concentración. Una reflexión filosófica necesaria”, En: Santos José (ed.), Dictadura y prisión política en Chile, Santiago de Chile, Editorial Pehuén, 2016 (En prensa) y Avila, Mariela, "Campos de concentración de las dictaduras latinoamericanas. Una mirada filosófica", En, Revista La Cañada. Pensamiento Filosófico Chileno, N 4, 2013

${ }^{24}$ Es precisamente en la última clase de su curso de 1976 donde Foucault hace una breve alusión al nazismo en relación al análisis de la categoría de racismo de Estado. Cfr., Foucault, Michel. Defender la sociedad. Buenos Aires, Fondo de Cultura Económica, 2001

${ }^{25}$ Es interesante notar el carácter que Foucault da a la práctica de la tortura en una entrevista del año 1977. Si bien allí el diálogo principal dice relación con el poder, la criminalidad, los castigos y la institucionalidad, Foucault lleva a cabo una distinción entre el idioma francés y el alemán relativo a la noción de razón. "En alemán, Vernuft tiene una significación mayor que "razón” en francés, (...) tiene una dimensión ética. En francés se le otorga una dimensión instrumental, tecnológica. En francés, la tortura, es la razón.” (Mi trad.) "La torture, c'est la raison", en Dit et Écrit II, p., 395. En este sentido, podemos decir que para Foucault la tortura no se constituiría más allá, o más acá, de la racionalidad para convertirse en algo "irracional", sino que por el contrario, guardaría un claro coeficiente técnico e instrumental.
} 
aquella mirada supuestamente aséptica y poco invasiva que el régimen punitivo legal consolida en el siglo XIX, en momentos de excepción descargaría toda su fuerza y violencia sobre aquellos cuerpos abandonados ${ }^{26}$ al margen del ámbito jurídico. En este sentido, indica Agamben: "La relación de excepción es una relación de bando. El que ha sido puesto en bando no queda sencillamente fuera de la ley ni es indiferente a esta, sino que es abandonado por ella, es decir que queda expuesto y en peligro en el umbral en que vida y derecho, interior y exterior se confunden." 27

Desde esta perspectiva, de cuño más agambeniana, pero que sin embargo, pretende seguir y "completar" la senda foucaulteana, sería posible observar que en un marco de excepción, la violencia y el terror administrados y ejercidos desde la institucionalidad de los aparatos estatales, actualizaría tanto aquel suplicio como aquel castigo, que parecían haber quedado sepultado por esa necesidad de cura y reinserción de las "almas" que promulgaban las tecnologías punitivas a fines del siglo XVIII.

Avanzando hacia el contexto latinoamericano, el abogado Roberto Garretón explica respecto a la relación entre la tortura y la excepcionalidad legal, que: "Los instrumentos internacionales de derechos humanos también han demonizado la tortura. Ella no puede practicarse jamás, ni aún en los llamado estados de excepción" ${ }^{28}$. Ahora bien, los gobiernos dictatoriales del Cono Sur $^{29}$, ignoraron completamente el rechazo y repudio internacional hacia la tortura, implementándola como herramienta de la doctrina de seguridad nacional. Durante las últimas dictaduras, las Juntas Militares suspendieron la legalidad de sus países, reemplazándola por un Estado ilegítimo, terrorista y asesino, cuyo blanco fue la totalidad de la población. Esta situación de excepcionalidad legal fue la que, precisamente, posibilitó la apertura y la puesta en marcha de espacios clandestinos, destinados a la tortura y desaparición de cuerpos particulares, principalmente de opositores políticos. Casi cualquier habitante del territorio nacional podía convertirse en un detenido, secuestrado, y eventualmente en un desaparecido. En este sentido, y respecto al caso chileno, Brian E.

\footnotetext{
${ }^{26}$ Aludimos a la noción de abandono acoplándonos al uso que hace Agamben del término bando, utilizado por Jean-Luc Nancy, quien dice: "Abandonar es entregar, confiar o librar a un poder soberano, y entregar, confiar o librar a su bando, es decir a su proclamación, a su convocatoria y a su sentencia. El abandono se produce siempre con respecto a una ley. La privación del ser abandonado se mide por el rigor sin límites de la ley a la que se encuentra expuesto. El abandono no constituye una citación de comparecencia bajo una u otra imputación legal. Es una obligación de comparecer absolutamente ante la ley, ante la ley en su totalidad." Agamben, Giorgio, Homo sacer I. El poder soberano y la nuda vida, Valencia, Pre-textos, 2006, p., 80

${ }^{27}$ Agamben, 2007, Op., Cit., p., 133

${ }^{28}$ Garretón, Manuel, Una perspectiva desde el Derecho Internacional de los Derechos Humanos. En: Patricia Verdugo (Ed.), De la tortura no se habla. Agüero versus Meneses, Santiago de Chile, Catalonia, 2004, p., 147

${ }^{29}$ Consideramos necesaria una aclaración de carácter metodológico relativa al uso de la noción de Cono Sur, con la que aludimos a Chile, Argentina y Uruguay en su conjunto. Es Marcelo Raffin quien ilumina esta relación al mostrar un cúmulo de elementos comunes tanto a nivel interno como externo entre estos países. Entre estos elementos, nos referimos particularmente al lugar de la política en relación con la etapa dictatorial, signada por la suspensión de la normalidad jurídica, lo que da lugar a un ámbito de excepcionalidad legal. Cfr. Raffin, Marcelo, La experiencia del horror. Subjetividad y derechos humanos en las dictaduras y postdictaduras del Cono Sur, Buenos Aires, Del Puerto, 2006
} 
Loveman y Elizabeth Lira sostienen: "La dictadura militar afectó las vidas de todos los chilenos, pero a quienes fueron definidos como "enemigos" se los excluyó bajo las formas del "destierro, el encierro, el entierro", cuyas dramáticas consecuencias han persistido más de treinta años." 30

En efecto, aun considerando que el terror se desplegó y expandió en el espacio público en su totalidad, fue en los centros clandestinos de detención donde toda la violencia del poder soberano aparentemente superada por los gobiernos democráticos previos reapareció de manera potenciada, e incluso, desatada, desplegándose bajo un cúmulo de nuevas técnicas aprendidas y refinadas en escuelas de entrenamiento internacional. En esta línea, es interesante contemplar la relación existente entre el entrenamiento militar del Cono Sur y las escuelas militares internacionales, especialmente con el caso de la Escuela Francesa, cuya práctica en Argelia fue sistematizada y transmitida a los militares latinoamericanos $^{31}$. La primera reunión entre miembros de los servicios de seguridad e inteligencia de Chile, Argentina, Bolivia, Uruguay y Paraguay, en Santiago de Chile el año 1975, sentó las bases de lo que sería conocido como el Plan Cóndor. La convocatoria a dicha reunión, "(...) expresa la necesidad de unirse en la acción represiva contra el enemigo común de la subversión" 32 . Este plan de cooperación internacional, que posibilitaba el trabajo en conjunto entre los países del Cono Sur contra los disidentes políticos, permitía que estos fueran secuestrados, encerrados, interrogados y torturados en los diversos territorios por la autoridad militar del país. Incluso, el asesinato formaba parte de este pacto, que se caracterizaba por el ejercicio del terror, la violencia y la tortura sin referentes legales nacionales o internacionales.

Según testimonios, "(...) la tortura era la clave, el eje sobre el que giraba toda la vida del campo", y en este sentido, es posible pensar que era también el elemento que sacaba de sus límites físicos al campo de concentración. El uso desmedido de la violencia y el dolor tenía un claro efecto sobre la ciudadanía, que contemplaba con temor las existencias sufrientes de los reaparecidos, los cadáveres mancillados que aparecían en espacios públicos, e imaginaba el cruel destino de aquellos a quienes no volvía a ver. En este sentido, indica Raúl García: "La tortura, la muerte y la desaparición funcionaban como amenazas para la población, pues siempre se dejaban indicios -cuando no se operaba deliberadamente ante testigos- para que se supiera de las acciones y la violencia de la que eran capaces los militares."

En los centros clandestinos de detención se puso en marcha un plan sistemático y novedoso para aniquilar no sólo individuos, sino también subjetividades que se oponían al modelo político, económico, social, moral e incluso sexual, que las juntas militares buscaban imponer en el territorio latinoamericano. Sobre el uso de la tortura durante estos periodos políticos dice Pilar Calveiro: “(...) los campos de concentración daban una nueva

\footnotetext{
${ }^{30}$ Loveman y Lira, "Marco Histórico: Terrorismo de Estado y Tortura en Chile". En: Verdugo, Patricia (Ed.). De la Tortura no se habla. Agüero versus Meneses, Op., Cit., p. 206.

${ }^{31}$ Cfr., Robin, Marie-Monique. Escadrons de la mort, l'école française, Paris, La Découverte, 2008

${ }^{32}$ Raffin, Marcelo. Op., Cit., p., 160.
} 
posibilidad: usarla de manera irrestricta e ilimitada"33. La vida de la población no sólo no tenía ningún valor, sino que representaba un peligro que amenazaba con extenderse al resto del continente, y que por lo tanto, era necesario frenar a como diera lugar.

Desde esta perspectiva, los insumos desarrollados por Foucault bien podrían constituirse en un aporte para indagar estos sucesos. Y esto en particular, teniendo en cuenta el giro que presenta desde un poder institucional, centrado en el cuerpo, a un poder de corte más global, que se ejerce sobre la población en tanto conjunto de vidas con características comunes. Este giro, que Foucault sitúa en el último cuarto del siglo XVIII, muestra el desplazamiento de un poder que vigila cuerpos individuales sobre los que se descarga la pulsión del castigo, hacia la regulación y administración de las características vitales de un colectivo: la población. En este cruce, la población se convierte en el elemento sobre el que se desarrollaran y aplican diversas políticas y tecnologías, cuya meta es la extensión y protección de la existencia. Así, la vida biológica cobra un papel central al interior de la política, dando lugar a nuevas prácticas y saberes en la gestión de la existencia.

Foucault, recurre a la noción de racismo de Estado, que presenta en el curso de 1976 Defender la sociedad, para mostrar cómo aún dentro de un paradigma biopolítico, que busca potenciar la vida, el asesinato sigue teniendo lugar. Interesa ver aquí el modo en que la antigua figura del racismo se articula ahora como un mecanismo del Estado, a partir del que se puede establecer que ciertas vidas deben morir, y otras deben vivir. La raigambre biológica del racismo se manifiesta en el corte que se inscribe en el cuerpo de la población, separando vidas dignas, de existencias indignas. El racismo de Estado evidencia la manera en que, a la vez que se potencian ciertas formas de vida acordes al sistema político y económico, hay otros modos de vida considerados poco valiosos e incluso peligrosos, y que por lo tanto, es necesario exterminar. Foucault indica que este proceso de distinción de orden biológico, implica la construcción de un "otro" indeseable tanto a nivel discursivo, como simbólico y práctico, lo que permite que ciertas existencias sean vejadas, torturadas, y aniquiladas. Así, la valía de la vida se corresponde con la decisión estatal de regular e implementar ciertos modos de existencia deseables y rentables, frente a otros percibidos como nocivos y desestabilizadores. Ilustrador es el caso de Chile, y particularmente las palabras que general Gustavo Leigh Guzmán, comandante en jefe de la Fuerza Aérea, esbozó en su discurso el 11 de septiembre de 1973: "Tenemos la certeza, la seguridad de que la mayoría del pueblo chileno está contra el marxismo, está dispuesto a extirpar el cáncer marxista hasta las últimas consecuencias" "34. Lo biológico se refleja en el ámbito político, y se convierte en el elemento a regular, que posibilita la continuidad de la vida, a través del asesinato.

No obstante, es el propio Foucault quien indica que el recurso al racismo de Estado no sólo implica el asesinato, sino también el desconocimiento, la falta de valía política y la

\footnotetext{
${ }^{33}$ Calveiro, Pilar, Poder y desaparición. Los campos de concentración en Argentina, Buenos Aires, Colihue, 2008, p., 63

${ }^{34}$ Citado por Valdivia Ortiz de Zárate, Verónica. <“¡Estamos en guerra señores!” El régimen militar de Pinochet y el "pueblo" 1973-1980.> En: Revista Historia (Santiago), v.43, n.1, Santiago, junio de 2010.
} 
indignidad de los sujetos. Al respecto, en la última clase del curso del 1976, dice: "Desde luego, cuando hablo de dar muerte no me refiero simplemente al asesinato directo, sino también a todo lo que puede ser asesinato indirecto: el hecho de exponer a la muerte, multiplicar el riesgo de muerte de algunos o, sencillamente la muerte política, la expulsión, el rechazo, etcétera." " De este modo, la construcción de un "otro", disidente político, peligroso y sacrificable, guarda una relación directa con las diversas formas de tortura, y vejación, que se despliegan sobre cuerpos particulares, pero también con un cúmulo de prácticas sociales quizá menos visibles, pero que con igual violencia, se aplican sobre el cuerpo social de la población. Entre estas, citamos la persecución política, las detenciones ilegales, la exoneración, el exilio, tanto interno como externo, entre otras.

A partir de lo dicho, se podría considerar que la figura del racismo de estado es quizá, dentro del corpus foucaulteano, la que brindaría un mayor rendimiento en el análisis de otros contextos histórico-políticos. Y esto de modo particular, si se considera la ampliación que Foucault lleva a cabo de la noción de asesinato, extendiéndola al plano de la muerte indirecta. Dicha extensión sería la que uniría la reflexión del filósofo sobre los estados asesinos, a las prácticas de tortura, violencia, muerte y desaparición ejercidas, en este caso, por las Juntas Militares del Cono Sur. De hecho, es en este mismo curso dónde Foucault hace una alude al nazismo como el Estado que (...) "llevó hasta el paroxismo el juego entre el derecho soberano de matar y los mecanismos del biopoder." 36

Dado lo anterior, podríamos pensar que Agamben toma como punto de partida de sus indagaciones esta reflexión foucaulteana, para extenderla y forzarla hasta límites en que su origen parece perderse. En efecto, es Agamben quien analiza la figura del campo de concentración, convirtiéndola en un paradigma, que más allá de sus especificidades propias, permitiría iluminar otros sucesos. Según Agamben, el campo de concentración sería el espacio en el que se observaría con mayor claridad el abandono legal que sufre la vida, por lo que la tortura y la violencia, pueden recaer sobre ella sin que medien consecuencias.

Si volvemos a la tortura y su despliegue, se puede observar que en el caso de las dictaduras del Cono Sur, fue, precisamente, en los centros clandestinos de detención donde se aplicó con mayor fuerza y efecto, lo que la convirtió en una eficaz herramienta dictatorial. Tal como hemos indicado, en estos espacios de excepción no había ningún tipo de orden legal, por lo que las vidas que allí yacían estaban abandonados por la ley: cuerpos que se podían torturar, asesinar, e incluso, desaparecer. A esto parece referirse Rodolfo Walsh, cuando en su "Carta abierta a la Junta Militar" de la República Argentina, publicada el día del primer aniversario del golpe $\operatorname{militar}^{37}$, dice:

Colmadas las cárceles ordinarias, crearon ustedes en las principales guarniciones del país virtuales campos de concentración donde no entra

\footnotetext{
${ }^{35}$ Foucault, Op., Cit., 2001, p., 231

${ }^{36}$ Ibíd., p., 235.

${ }^{37}$ El día 25 de marzo de 1976, un día después de la publicación de esta carta abierta de denuncia, Rodolfo Walsh es secuestrado por un Grupo de tareas de la Escuela de Mecánica de la Armada. Su cuerpo nunca apareció, y su nombre integra hoy las listas de desaparecidos durante la última dictadura militar argentina.
} 
ningún juez, abogado, periodista, observador internacional. El secreto militar de los procedimientos invocados como necesidad de la investigación, convierte a la mayoría de las detenciones en secuestros que permiten la tortura sin límite y el fusilamiento sin juicio. ${ }^{38}$

Precisamente, la tortura sin límites de la que habla Walsh abriría un ámbito intermedio entre la vigilancia y el castigo: una vigilancia persistente aunque no siempre visible, y un castigo que constantemente puede ser actualizado sobre la población. Las juntas militares no sólo consideraban que había almas disidentes que reformar, sino también cuerpos rebeldes que castigar. Podemos decir entonces, que durante las últimas dictaduras militares del Cono Sur, el ejercicio de la tortura actúo como un ojo vigilante, en tanto ordenador y organizador del cuerpo social, haciendo siempre presente un castigo por cumplir, cuya mayor materialización se evidenciaba a través de una suerte de actualización del suplicio con su doble juego de visibilidad e invisibilidad, en los centros clandestinos de detención.

\section{Conclusión}

Como hemos visto, la utilización de las categorías analíticas de Michel Foucault en sucesos políticos vinculados a la excepcionalidad legal no está exenta de dificultades. Se requiere de precisiones para que estos aportes tengan un rendimiento teórico oportuno. Sobre todo, si lo que se busca es iluminar los episodios de tortura ocurridos en el marco de las dictaduras latinoamericanas, se debe tener presente que los análisis sobre el suplicio, de modo particular, realizados por Foucault, se insertan en un régimen de comprensión que es distante al régimen punitivo implementado en la sociedad disciplinaria.

Lo que hemos presentado aquí ha pretendido evaluar la pertinencia del uso de ciertas categorías del corpus analítico foucaulteano para pensar algunos sucesos de las recientes dictaduras latinoamericanas, y de modo específico, la práctica de la tortura. En ese sentido, nos hemos preguntado si aquellas categorías que Foucault muestra operando en distintos periodos históricos, podrían ser herramientas analíticas útiles para reflexionar sobre nuestra historia reciente. Nuestra respuesta primera respuesta a tales interrogantes va en la línea de la cautela, pues consideramos que las categorías no pueden simplemente trasplantarse y ser utilizadas para pensar los diversos procesos y acontecimientos históricos. Esto no quiere decir no puedan ser utilizadas, pero que sí que implican un trabajo de reflexión, e incluso, de adaptación.

Se trata, ante todo, de tener en vista que el criterio que Foucault maneja para desarrollar su reflexión y análisis, es el de la productividad del poder, vale decir, aquello en

\footnotetext{
${ }^{38}$ Walsh, Rodolfo, Operación Masacre, Buenos Aires, De la flor, 2000, p., 121-122
} 
lo que es ajeno a la violencia, al exterminio, o a la simple prohibición o negación. En síntesis, el suplicio al que atiende Foucault forma parte de una lógica del poder soberano, y la tortura en los espacios de excepcionalidad, se integra, a su vez, a un momento de suspensión del derecho.

Quedan sin embargo algunas preguntas, que esta propia reflexión habilita, y que esperamos desarrollar en otro momento. La primera de ellas dice relación con el estatuto productivo de la tortura: ¿hasta qué punto la tortura no es también un dispositivo de producción de saber? Desde luego, un saber que tiene relación con la delación, con la información de nombres, domicilios y vínculos, pero que, con todo, moviliza la maquinaria del terrorismo de Estado. Desde esta perspectiva, no sería inoportuno preguntarse por los parentescos de la tortura con los dispositivos confesionarios a los que Foucault dirigió su atención hacia el final de su obra, y en la misma óptica, la tortura no sería una práctica que abandone totalmente el criterio de la positividad del poder.

Por otra parte, queda la interrogante que se desprende de la interpretación de Agamben: ¿Hay un saldo de soberanía - de aquella racionalidad en la que cobra sentido el suplicio- al interior de la lógica disciplinaria? ¿Es tan radical el quiebre entre ambos modos de implementarse el poder? Desde luego, para ello habría que acudir a la lectura que Agamben hace de Carl Schmitt para intentar descifrar si la racionalidad del "amigoenemigo" forma parte, ya sea del poder soberano en la que tiene lugar el suplicio, o de la práctica de la tortura que tiene lugar en el terrorismo de Estado, al amparo de la excepcionalidad. En definitiva, ¿es la tortura una recomposición del poder soberano, bajo la lógica del "amigo-enemigo"? ¿Qué relaciones podrían encontrarse entre esta cuestión y el "racismo de Estado" del que Foucault dio algunas luces en 1976?

No podemos, sin embargo, asumir estos amplios desafíos en esta oportunidad, aunque nos permitimos sugerirlos como futuras eventuales líneas de investigación. Con todo, nuestro propósito ha sido hacernos cargos de las dificultades que plantea el uso del aparato analítico de Foucault para iluminar momentos oscuros de la historia latinoamericana. Esperamos haber cumplido, en mayor o menor medida, con tal propósito, que más que un carácter de clausura, busca mostrar un problema y revisar algunas de sus posibles y múltiples soluciones.

\section{Bibliografía}

Agamben, Giorgio, Homo sacer I. El poder soberano y la nuda vida, Valencia, Pre-textos, 2006.

Agamben, Giorgio, Estado de Excepción, Buenos Aires, Adriana Hidalgo, 2007. 
Agamben, Giorgio. Lo que queda de Auschwitz. El archivo y el testigo. Pre-textos, Valencia, 2000.

Avila, Mariela, "Campos de concentración de las dictaduras latinoamericanas. Una mirada filosófica”, En Revista La Cañada. Pensamiento Filosófico Chileno, № 4, 2013.

Avila, Mariela, "Entre policía y políticas. Derivas de un concepto filosófico” En: Yuing, Tuillang y Karmy, Rodrigo, Biopolíticas, Gobierno y Salud Pública. Ocho libros, Santiago, 2014.

Avila, Mariela, "Dictaduras Latinoamericanas y campos de concentración. Una reflexión filosófica necesaria”, En: Santos José (ed.), Dictadura y prisión política en Chile, Santiago de Chile, Editorial Pehuén, 2016.

Calveiro, Pilar, Poder y desaparición, Buenos Aires, Colihue, 2008.

Cassigoli, Isabel, "El derecho del Estado (de excepción) y la política del hombre" En: Karmy, Rodrigo, Políticas de la interrupción. Ensayos sobre Giorgio Agamben. Escaparate, Santiago, 2011.

Foucault, Michel, Las palabras y las cosas. Una arqueología de las ciencias humanas. Siglo XXI Editores, Buenos Aires, 2003.

Foucault, Michel, Vigilar y Castigar: Nacimiento de la prisión, México, Siglo XXI editores, 2005.

Foucault, Michel, Defender la sociedad. Buenos Aires, Fondo de Cultura Económica, 2001 Foucault, Michel, Microfísica del poder, Madrid, La Piqueta, 1992.

Foucault, Michel, "La torture, c'est la raison", en Dit et Écrit II, Quarto-Gallimard, Paris, 2008.

García, Raúl, Micropolíticas del cuerpo. De la conquista de América a la última dictadura militar, Buenos Aires, Biblos, 2000.

García Villegas, René, Soy Testigo. Dictadura, tortura, injusticia. Santiago de Chile, Editorial Amerindia, 1990.

Garretón, Manuel, "Una perspectiva desde el Derecho Internacional de los Derechos Humanos", En: Patricia Verdugo Editora, De la tortura no se habla. Agüero versus Meneses Santiago de Chile, Catalonia, 2004.

Karmy, Rodrigo, Políticas de la interrupción. Ensayos sobre Giorgio Agamben. Escaparate, Santiago, 2011.

Loveman y Lira, "Marco Histórico: Terrorismo de Estado y Tortura en Chile". En: Verdugo, Patricia (Ed.). De la Tortura no se habla. Agüero versus Meneses, Santiago de Chile, Catalonia, 2004.

Mendiola, Ignacio, Habitar lo inhabitable. La práctica político-punitiva de la tortura, Barcelona, Edicions Bellaterra, 2014.

Mulhe, María, "Sobre la vitalidad del poder: una genealogía de la biopolítica a partir de Foucault y Canguilhem" En: Lemm, Vanessa, Michel Foucault: neoliberalismo y biopolítica, Ediciones Universidad Diego Portales, 2010.

Peris Blanes, Jaume. La imposible voz. Memoria y representación de los campos de concentración en Chile: la posición del testigo. Cuarto propio. Santiago, 2005. 
Raffin, Marcelo, La experiencia del horror. Subjetividad y derechos humanos en las dictaduras y postdictaduras del Cono Sur. Buenos Aires, Del Puerto, 2006.

Rancière, Jacques. “Biopolítica o política?” En: El Tiempo de la igualdad. Herder, Barcelona, 2011.

Reszczynski, Katia, Rojas, Paz y Barceló Patricia. Tortura y resistencia en Chile, Santiago de Chile, Ediciones Radio Universidad de Chile, 2013.

Reyes Mate, Manuel, Memoria de Auschwitz. Actualidad moral y política. Trotta, Madrid, 2003.

Robin, Marie-Monique, Escadrons de la mort, l'école française , Paris, La Découverte, 2008.

Salinas, Adán, La semántica biopolítica. Foucault y sus recepciones. Cenaltes Ediciones, Madrid, 2014.

Seminario Internacional, Tortura, aspectos médicos, psicológicos y sociales. Prevención y tratamiento. Editado por el Equipo de denuncia, investigación y tratamiento del torturado y su núcleo familiar del Comité de Defensa de los Derechos del Pueblo, Santiago, 1990.

Thayer, Willy, El fragmento repetido. Escritos en estado de excepción. Metales pesados, Santiago, 2006.

Traverso, Enzo, La historia como campo de batalla. Interpretar las violencias del siglo XX. Fondo de Cultura Económica, Buenos Aires, 2012.

Verdugo, Patricia, De la Tortura no se habla. Agüero versus Meneses, Santiago de Chile, Catalonia, 2004.

Walsh, Rodolfo, Operación Masacre, Buenos Aires, De la flor, 2000.

\section{Bibliografía on-line}

Arendt, Hannah, Comprensión y política. Las dificultades de la comprensión. Disponible en: www.omegalfa.es/titulos.php?letra=\&pagina=3 (Consultado el 14 de febrero de 2016) Avila, Mariela, "Campos de concentración de las dictaduras latinoamericanas. Una mirada filosófica", En: Revista La Cañada. Pensamiento Filosófico Chileno, $\mathrm{N}^{\circ}$ 4, 2013. En: http://www.xn--revistalacaada-0nb.cl/uploads/articulo/archivo/A11_AVILA_pdf.pdf

(Consultado el 24 de marzo de 2016)

Guglielmi, Flavio Iván, "Los métodos punitivos y la economía de castigo durante la última dictadura cívico-militar argentina. ¿El regreso del poder soberano?” En: http://hum.unne.edu.ar/postgrado/eventos/coloquio_filo/coloquio_filo.htm (Consultado el 15 de marzo de 2016)

Santos-Herceg, José, "La tortura: todo es cuerpo", En: Revista de la Academia, Vol. 20, Año 2015. (Consultado el 29 de febrero de 2016)

Valdivia Ortiz de Zárate, Verónica, <"¡Estamos en guerra señores!” El régimen militar de Pinochet y el "pueblo" 1973-1980.> En: Revista Historia (Santiago), v.43, n.1, Santiago, junio de 2010. (Consultado el 10 de julio de 2016) 